\title{
L1 Use in L2 Academic Essays: A Study of L1 Arabic Writers' Views
}

\author{
Nahla N. Bacha ${ }^{1}$ \\ ${ }^{1}$ Department of English, Lebanese American University, Lebanon \\ Correspondence: Nahla Nola Bacha, Department of English, Lebanese American University, Lebanon. E-mail: \\ nbacha@lau.ed.lb
}

$\begin{aligned} & \text { Received: October 31, } 2017 \quad \text { Accepted: November 20, } 2017 \quad \text { Online Published: December 23, } 2017 \\ & \text { doi:10.5539/ijel.v8n2p15 }\end{aligned}$ URL: http://doi.org/10.5539/ijel.v8n2p15

\begin{abstract}
Research findings indicate conflicting views as to interference from L1 rhetorical patterns in the essays written by students whose first language is not English. Essays are still considered important for required assignments and exams in institutions of higher learning, but the challenge for L1 Arabic students is to express their ideas clearly. Although there have been studies of the use of L1 in L2 writing, there are very few rigorous ones done on L1 Arabic texts in Lebanon and specifically from the students' viewpoint. This study aims to evaluate, holistically and analytically, according to language, organization and content, the expository academic essays written by first year university L1 Arabic students and to examine any significant correlation between these scores and the quality of these essays through content analysis. In addition, students' perceptions of any problems they have in writing the academic essay are surveyed through a questionnaire. Results indicate a significant positive correlation between students' essay scores and the content analysis. However, findings from the student questionnaire revealed that they do not view any significant interference from L1 nor any significant problems in writing the academic essays which are contrary to the essay scores and content analysis results. Recommendations are made for L2 contexts and future research.
\end{abstract}

Keywords: L2 writing, L1 Arabic students, academic essays, Lebanon

\section{Introduction}

\subsection{Statement of the Problem}

Writing well in English at tertiary levels has always been on the agendas of English medium universities as it is important for students' success in their studies and careers (Belcher, 2006; Hyland, 2016; McCune, 2004; Paltridge, 2004). Recently, this issue has become even more problematic and urgent as more teacher complaints mount about the writing weaknesses of students (continual personal communication with discipline teachers at the institution and at international TEFL/TESOL and linguistic conferences 2013-2017). It is well known that many of these students face problems in writing the required academic texts in their disciplines (Hyland, 2013; Grabe \& Kaplan, 2014). Is this due to first language (L1) interference and/or a lack of instruction and thus a lack of awareness of what is required (McCune, 2004). While early research has indicated that L1 rhetorical patterns and linguistic devices negatively interfere with second language (L2) writing (e.g., the seminal work of Kaplan, 1966); research has shown that with certain specific instructional methods towards disciplinary writing students showed ability to develop their L2 writing in their discipline communities (Connor, Nagelhout, \& Rozycki, 2008; Feez, 1998; Ferris \& Hedgcock, 2004; Hyland, 2017; Johns, 2001; Mukattash, 2003; Swales, 1990 among others). Thus, this study aims to investigate possible cause(s) of any writing problems that L1 Arabic students have in writing academic essays, one required genre at the university level.

\subsection{Significance of the Study}

There is little or no research in this area in Lebanon where L1 Arabic students struggle in writing in L2. Some text analysis has identified the problems in their L2 writing (Bacha, 1997, 2002; Mukattash, 2003), which has helped to identify strategies that could help the students, but there are few or no rigorous studies as to what causes these problems from the L2 students' standpoint in Lebanon. This study hopefully can contribute knowledge so that teachers could be better equipped to help their students in the context of the present study and in other similar ones.

\section{Review of Literature}

There have been conflicting views why the writing of L2 students is "weak" and has a "strange feel" to it ranging 
from inter language transfer from students' native language(s) to inadequate or no effective instruction in the target language. This has left writing teachers to search for ways to help students with their academic writing in order to cope with the requirements of higher education and the professional writing demands in their careers.

A challenge for L2 writers in English is the text organization and sentence structure of essays, research papers, and assignments of various genres required in academic settings (e.g., Hyland, 2017; Kroll, 1990; Swales, 1990; Paltridge, 2004 among others). Some research has indicated that written English discourse is linear and Arabic is not (Kaplan, 1966; Purves, 1988) which studies attribute to the cause of difficulties for L1 Arabic students writing in English. This may cause negative transfer into the L2 writings. Other researchers, nevertheless, do show how positive transfer may occur, but this has been mainly in vocabulary (Odlin \& Yu, 2016) in various languages. Some studies have focused on L1 Arabic negative transfer on L2 English texts (Bacha, 1997; Hatim, 1997; Mukattash, 2003; Sa'adeddin, 1989).

Even though Kaplan himself later qualified his model (Kaplan, 1987; Grabe \& Kaplan, 1996), which then had focused only on the paragraph level and was not related to academic writing, researchers still argue in favor of "cultural" and first language (L1) influences in the target language (Alonso, 2016; Connor, 2002; Connor \& Kaplan, 1987; Coulthard, 1994; James, 2014; Jarvis \& Crossley, 2012; Van Weijen, Vand den Bergh, Rijlassrsdan, \& Sanders, 2009; Zamel, 1997). Petric, (2005) found after instruction of argumentation writing to L1 Russian tertiary students that their thesis statements had a more linear type of thought in the essays. Raising the students' awareness of the cultural writing differences between Russian and English rhetoric helped these students to become less digressive when writing in English. Other researchers also found interference in the L2 writing from L1 rhetorical patterns. For instance, Hatim (1997) studied the differences between Arabic and English and Hinds (1983) between Japanese and English.

An example of a study of interest on the organizational patterns of introductions written by L1 Arabic students is a doctorate thesis by Al-Qahtani (2006) in the USA, which showed through qualitative text analysis that native speakers of Arabic write expository essay introductions very differently to those written by native speakers of English. L1 Arabic students have most difficulty in organizing their ideas in their introductions of expository essays (e.g., Bacha, 2002; Mukattash, 2003). In fact, the L1 Arabic writers tend to have very long introductions and include content often not related to the topic and often start their introductions by irrelevant and unnecessary reference to past historical facts along with very long sentences set off by commas. In the English tradition, there are certain conventional expectations in writing introductions which differ from those in Arabic. Introductions in essays in the Western tradition normally begin with a hook to gain the readers' interest, some relevant brief background information on the topic, definitions of any key terms and an explicit mention to the main ideas placed in a statement (referred to as the thesis statement) which normally occurs at the end of the introduction upon which the essay is organized and developed.

On a macro scale, and contrary to some studies that argue for the inadequacy of the essay in academic writing, the essay is still considered an important genre in the academy and the professions in its transference of organizational and metacognitive skills to other text genres (Bacha, 2002; Johnson, Smagorinsky, Thompson, \& Fry, 2003). Much has been written on the organization of the expository five-paragraph essay according to the Western tradition and much has been recommended for the teaching/learning situation (e.g., Kroll, 1990; Paltridge, 2004). Johnson et al. (2003) relate a student teacher's experiences in teaching a high school class where the long thought of essay as being restrictive and archaic was found to be useful in affording a framework in which students could organize their thoughts and at the same time be innovative in including a variety of sentence structure, using lively and appropriate vocabulary, and including creative ideas. The essay format, thus, avails itself as a framework for different discipline types of writings. McCune (2004) ran a small scale longitudinal study on first-year psychology students' learning of the academic essay related to the discipline and found that students need help in conceptualizing their ideas in an overall organized format. McCune states

The body of literature relating to students' conceptions of essay writing suggests the need to provide help for students on their essay writing that goes beyond standard written feedback and handouts (p. 279).

In addition, the genre school of thought further supports the notion that there are various discourse types with different organizational patterns to which students in the academy need to be initiated such as research papers, business and laboratory reports and so on in order to be successful in their chosen subject (Bhatia, 2004; Connor \& Johns, 1990). Some other research in Dutch, French, Arabic and Chinese has found that students use L1 writing strategies when writing various genres in L2 to various degrees with mainly the lower proficient students depending more on $\mathrm{L} 1$. These findings are important in raising awareness of the differences and thus implementing suitable instruction in the L2 teaching/learning context (Ansarimoghaddam \& Tan, 2014; Lally, 2000; Nor, Hua, 
\& Ibrahim, 2012; Wang \& Wen, 2002; Woodall, 2002).

Insights over semesters at the university in this study in the English academic courses have indicated that the essay introductions have often been very long paragraphs and normally begin by giving a history that may extend from the "beginning of time" or some remarks that are often not relevant to the topic. Further, the main ideas or purpose of the essay may not be adequately indicated, coherent, developed and supported in the body of the essay. Conclusions do not wrap up the essay reinstating the main ideas and often include new ideas giving the impression that the writer is beginning a new text. This study hopes to study a sample of L1 Arabic students' essays on entry to the university as to organization and sentence structure to examine any negative transfer from L1 onto L2 writing.

\section{Research Questions}

This study focuses on two research questions:

- To what do students view L1 interference is due in their academic essays, and

- To what extent is there a relationship among the essay content analyses, holistic and analytic scores and student survey results?

\section{Method}

\subsection{Participants}

Out of an intact student population of one hundred and twenty five students who were attending the first required academic English language course at an English medium university in Lebanon at the time of the study, ninety three students sat for the essay and filled out the survey. Their ages ranged from 18-22 with a mean age of 20.5. Ethical considerations in obtaining informed consent and keeping the essays and questionnaires anonymous were taken into account. Below are demographic details of the participants according to gender, major, nationality, native language, study language (the language the students in which they studied subjects in high school), languages students perceived spoken and written well. What is important to note is the multilingual profile of the students and thus the possible interference in the target language. The sample is representative of the population. Although demographic information of the participants is provided, it is not the purpose of this study to investigate the relationship of these variables to the causes of the participants problems in essay. However, it is interesting to have knowledge of the complexity of their backgrounds which would be interesting for future research.

Table 1 indicates that both genders are represented almost equally.

Table 1. Participants according to Gender

\begin{tabular}{lllll}
\hline & Frequency & Percent & Valid Percent & Cumulative Percent \\
\hline Female & 39 & 41.9 & 41.9 & 41.9 \\
Male & 54 & 58.1 & 58.1 & 100.0 \\
Total & 93 & 100.0 & 100.0 & \\
\hline
\end{tabular}

Table 2 shows the various majors at the university are represented with the majority following an engineering discipline and business.

Table 2. Percentage of Participants according to Major

\begin{tabular}{lllll}
\hline & Frequency & Percent & Valid Percent & Cumulative Percent \\
\hline Freshman & 8 & 8.6 & 8.6 & 8.6 \\
Nursing & 3 & 3.2 & 3.2 & 11.8 \\
Engineering & 27 & 29.0 & 29.0 & 40.9 \\
Architecture & 9 & 9.7 & 9.7 & 50.5 \\
Pharmacy & 13 & 14.0 & 14.0 & 64.5 \\
Nutrition & 4 & 4.3 & 4.3 & 68.8 \\
Comp.Sc. & 5 & 5.4 & 5.4 & 74.2 \\
Biology & 6 & 6.5 & 6.5 & 80.6 \\
Business & 16 & 17.2 & 17.2 & 97.8 \\
Pol.Science & 2 & 2.2 & 2.2 & 100.0 \\
Total & 93 & 100.0 & 100.0 & \\
\hline
\end{tabular}


Figure 1 indicates the complexity of the nationalities at the university. However, there is a majority of Lebanese nationals, but many of these nationals have a dual nationality and often three. Arabic, however, was the mother tongue of all students in this sample.

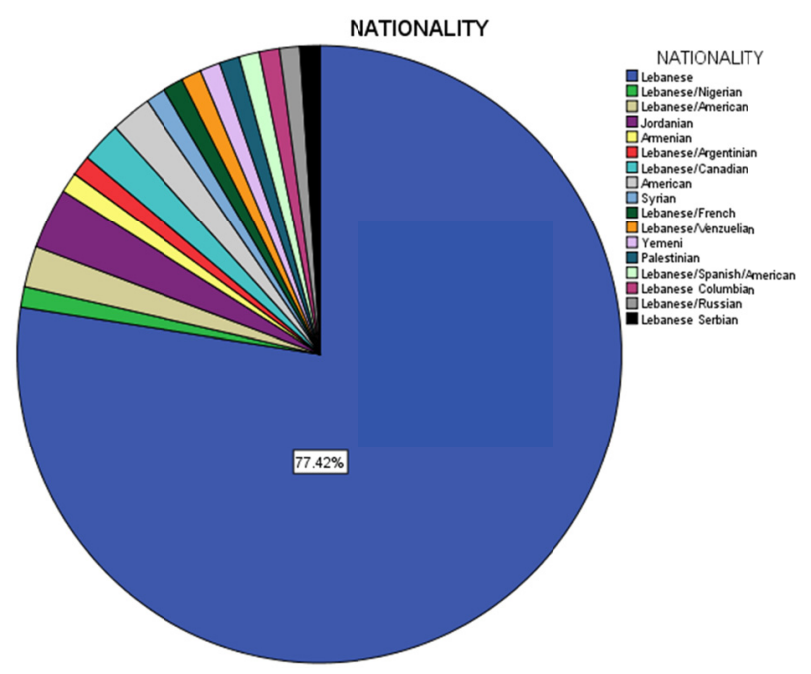

Figure 1. Participants according to nationality

\section{Percent Students According to School Study Language}

Students are mainly French educated (58.\%); that is to say that their studies in high school are done in French (French medium schools) although they do learn English along of course with Arabic as their first and native language. Although not as high, English educated students made up $36.6 \%$ of the population (English medium schools) which shows an increasing demand for English in the country. The rest, a minor percentage of 1.08 made up the rest mainly Armenian, Spanish and Arabic educated.

\subsection{Perceptions of Participants on How Well They Speak}

Students, when asked what languages they speak well, indicated quite a number. However, the majority are trilingual speaking Arabic/French and English. Specifically, the sample in this study had $25.81 \%$ bilingual speakers (Arabic and English) and 37.63\% trilingual (Arabic, English and French). A small percentage (1/3) were a mixture of Arabic/English along with Spanish or Armenian.

\subsection{Perceptions of Participants on How Well They Write}

The survey of the students' views shows that although students are L1 Arabic speakers, they perceive themselves writing French better, but the majority $30.11 \%$ view their writing skills well in three languages: Arabic, French and English. A large number of 25.81\% viewed they write well in Arabic and English and the rest, almost 50\%, viewed either they write well in French (8.60\%), English (11.83\%) and the rest were divided over Arabic and Spanish or Armenian. Again, this is a great challenge for the teaching/learning of the target language, English, in the L2 classroom. It was interesting to see that although many students view they speak a few languages well, they may not necessarily view they write well in these languages.

\subsection{Instruments}

A mixed method research design using both qualitative and quantitative data was used in the present study. A survey (Appendix A) to tap the perceptions of the participants as to how well they perceive their spoken and written proficiency are, what they consider the causes of their problems, (according to organization, vocabulary, grammar, sentence structure, French and/or Arabic), in writing the diagnostic essays was administered to the first year students upon entrance. The essays were qualitatively evaluated by content analysis, and quantitatively by holistic and analytic scores for the same criteria as in the questionnaire: organization, vocabulary, grammar, sentence structure by the researcher). The relation between the content analysis and writing quality as determined by the essay holistic and analytic scores was carried out. The SPSS v. 20 was used to analyze the quantitative data and a Spearman Correlation Coefficient two tailed statistical test at a significance level of less than 0.5 was carried out to correlate the holistic and analytic scores. Text analysis results were compared with the questionnaire and 
quantitative scores.

\subsection{Procedure}

A diagnostic essay on the topic giving reasons why (or why not) Life is Fair, was written at the beginning of the semester for one hour by the ninety three L1 Arabic university entering students. A random sample of twenty five essays were selected from the ninety three and qualitatively analyzed according to an essay rubric tested for reliability and validity for content, organization, vocabulary, language use (grammar and sentence structure) and mechanics (punctuation, spelling, capitalization) (Jacobs, Zinkgraf, Wormouth, Hartfiel, \& Hughey, 1981). Also, out of 150 surveys distributed to these five English classes to obtain the students' perceptions on any language shortcomings due to interference or problems, 93 participants responded (a $62 \%$ response rate). There were 10 questions on a likert scale of 1-5 (1never to 5 always) (see Appendix A).

\section{Results and Discussion}

Results are given according to the two research questions.

5.1 Research Question 1: To what extent do students view L1 interference is due in their essay writing?

Although the findings in Table 3 indicate that students do not admit to having a lot of problems, results do show that the students significantly perceive translating from French. Arabic also is viewed as a significant problem but not as high as French is. Surprisingly, however, students view their grades as being above $80 \%$ with organization, vocabulary and grammar being their least worry when writing an English essay. It is interesting though that although Arabic and French significantly affect their writing, it is not highly significant contrary to what some researchers have noted (Kaplan, 1966, Grabe \& Kaplan, 1996; Purves, 1988). Results also indicate that the students perceive that they know how to write an essay which assumes that they have had some instruction previously.

Table 3. Mean scores of participants perceptions on the problems that affect essay writing

\begin{tabular}{llllll}
\hline Problem & Mean & Std. Deviation & Minimum & Maximum & Significance \\
\hline Arabic & 2.2151 & 1.05139 & .00 & 5.00 & 0.097 \\
French & 1.5699 & 1.46256 & .00 & 5.00 & $0.000^{*}$ \\
Armenian & .2151 & .80554 & .00 & 5.00 & 0.123 \\
Organization & 2.2688 & .88637 & 1.00 & 5.00 & 0.123 \\
Vocabulary & 2.4946 & .89228 & 1.00 & 5.00 & 0.675 \\
Grammar & 2.3226 & .84906 & 1.00 & 4.00 & 0.168 \\
Arabic Tran & 1.9247 & 1.11547 & .00 & 5.00 & $0.008^{*}$ \\
French Tran & 2.0000 & 3.59045 & .00 & 3.00 & $0.001^{*}$ \\
Knowledge & 1.5376 & .74541 & 1.00 & 4.00 & 0.423 \\
Grades & 3.6882 & .98883 & 1.00 & 5.00 & 0.124 \\
\hline
\end{tabular}

Table 4 indicates that $87.1 \%$ of the students perceive themselves knowing how to write essays, while only $12.9 \%$ of the students admit to not knowing, which in comparison is a very small percent. Interestingly, Tables 4 and 5 show a high significant relation $(\mathrm{p}=.001)$ between this perceived knowledge of essays and perceived high grades. This shows that students' views are consistent.

Table 4. My essay writing problems are because I do not know how to write essays

\begin{tabular}{lllll}
\hline & Frequency & Percent & Valid Percent & Cumulative Percent \\
\hline Never & 56 & 60.2 & 60.2 & 60.2 \\
Rarely & 25 & 26.9 & 26.9 & 87.1 \\
Sometimes & 11 & 11.8 & 11.8 & 98.9 \\
Most of the time & 1 & 1.1 & 1.1 & 100.0 \\
Total & 93 & 100.0 & 100.0 & \\
\hline
\end{tabular}


Table 5. Significant correlation between participant perceptions of essay knowledge and perceived grades using spearman correlation statistical test

\begin{tabular}{|c|c|c|c|c|}
\hline & & & Grade & Knowledge \\
\hline \multirow[t]{6}{*}{ Spearman's rho } & BGRADE & Correlation Coefficient & 1.000 & $-.430^{* *}$ \\
\hline & & Sig. (2-tailed) & . & .000 \\
\hline & & $\mathrm{N}$ & 93 & 93 \\
\hline & PKNOW & Correlation Coefficient & $-.430^{* *}$ & 1.000 \\
\hline & & Sig. (2-tailed) & .000 & . \\
\hline & & $\mathrm{N}$ & 93 & 93 \\
\hline
\end{tabular}

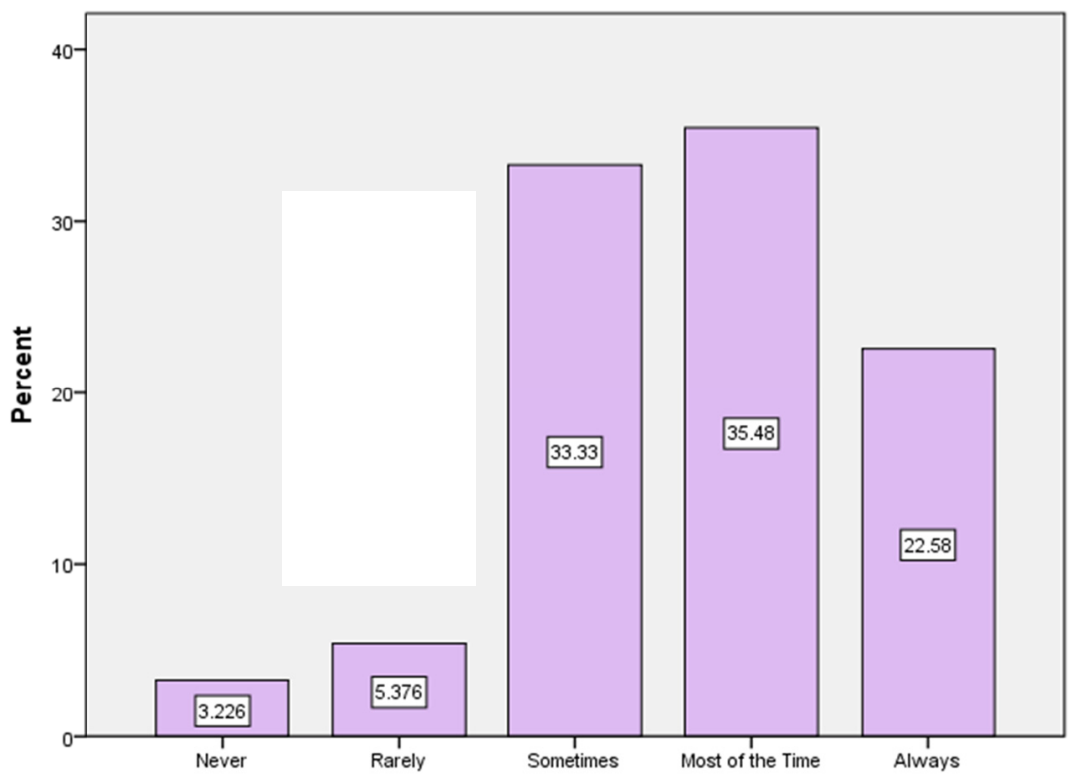

Figure 5. I earn grades over $80 \%$ in my essay writing

5.2 Research Question 2: To what extent is there a relationship among the essay content analyses, holistic and analytic scores and student survey results?

Are the findings mentioned above apparent in the students' essay writing? Below in Table 6 are the results of the holistic and analytic scores of five essays selected at random and one qualitative evaluation of an essay selected at random. The holistic scores confirm a positive relationship with the relatively low total analytic scores. However, the students' perceptions above indicated otherwise as most perceived receiving grades over $80 \%$. These findings confirm research in the field that students' perceptions of their own work are often higher than they actually are according to instructors' ratings (Kroll, 1990; Bacha, 2002).

Table 6. Participants' sample essay scores

\begin{tabular}{llllllll}
\hline Essay & $\begin{array}{l}\text { \%Holistic } \\
\text { Score }\end{array}$ & $\begin{array}{l}\text { Content } \\
30 \max \end{array}$ & $\begin{array}{l}\text { Organization } \\
20 \max \end{array}$ & $\begin{array}{l}\text { Vocabulary } \\
20 \max \end{array}$ & $\begin{array}{l}\text { Language } \\
25 \max \end{array}$ & $\begin{array}{l}\text { Usechanics } \\
10 \max \end{array}$ & $\begin{array}{l}\text { Total Analytic } \\
\text { Score }\end{array}$ \\
\hline $1(\mathrm{FE})$ & 60 & 10 & 11 & 11 & 14 & 3 & 58 \\
$2(\mathrm{FE})$ & 65 & 22 & 15 & 15 & 15 & 4 & 71 \\
$3(\mathrm{AE})$ & 70 & 22 & 14 & 14 & 18 & 4 & 72 \\
$4(\mathrm{FE})$ & 70 & 28 & 18 & 16 & 12 & 2 & 76 \\
$5 \mathrm{EE})$ & 65 & 15 & 16 & 14 & 14 & 5 & 64 \\
\hline
\end{tabular}

Holistic and analytic scoring according to Jacobs' et al. (1981) assessment rubric (Holistic and analytic scores do not necessarily have to add up to the same total.) FE, French educated, AE, Arabic educated, EE, English educated. 


\subsubsection{Essay Sample: French Educated Student, L1 Arabic}

Below is a sample of the essay written by a L1 Arabic participant.

Life is introduced to most of us as a period of time, in which we are supposed to work or "fight" for everything that is good, and always seek what is right. But is this life fair for all humans?

Generally, and philosophically speaking, considering that nearly all humans cannot choose where or in what circumstances they are born in. I'm sure that all the poor people in the world would've referred existing in more comfortable situations.

Also, the act that everyone spend approximately 25 years studying, in order to find decent jobs to produce money, and then spend all their money on making their lives a bit longer, because they could die any minute. Doesn't seem quite fair to me.

At last, in our daily life, we encounter people whose parents have power an authority, that can get them to places even if the didn't deserve it, while there are people who have worked hundreds of times more harder, and don 't have a fair chance.

There are plenty of reasons why life isn't fair. But nonetheless, we will have to live it and accept everything that is offered for us.

\subsubsection{Content Analysis of a Sample Essay}

- There is no clear thesis statement which states how the essay will be organized and what ideas will be developed. Also, there are no clear topic sentences nor evidence given to support any idea that is given.

- There is no organizational cohesion in the necessary three essential parts of an introduction.

- Sentence structure is weak and essay reads as if it is spoken. There is little or no academic characteristic to the essay.

- There seems to be transfer from Arabic writing models in that the student began with a too general statement about life and also the conclusion does not logically end the essay nor restate a thesis statement (which is not there to begin with).

\section{Conclusion}

Although the study is limited and the results cannot be generalized, they do indicate a relationship between the holistic rated essay scores and the analytic rated scores and the qualitative content analysis. However, the perception of the students on the survey showed little relation with the content essay text analysis of the students. Preliminary results from the survey showed that students perceive knowing how to write an essay, but in actual fact this did not appear when the essays were analyzed qualitatively nor did this appear through the holistic and analytic scores which were low on average. These results show most importantly that students' knowledge of their work is either misinformed by past practices or student expectations are higher than that of their instructors'. This has to be investigated early on in the course if students are to understand what essay writing is and what the expectations are.

This research has wide implications for teaching/learning essay writing through text analysis. It is recommended that instructors raise student's awareness and expectations of "good" essay writing. This can be done through showing samples of good essays, instruction through group work and individual conferences. The time and effort given to the students is valuable and worthwhile. Future research is needed on larger samples, different English levels and different rhetorical modes and genres and taking into account the participants' demographic information. There is much to discover, to teach, and to learn.

\section{Acknowledgments}

The research was sponsored by the University Research and Development Council (URCD) Lebanese American University, Lebanon.

\section{References}

Alonso, R. A. (2016). Crosslinguistic influence in second language acquisition. Bristol: Multilingual Matters.

Al-Qahtani, A. (2006). A contrastive rhetoric study of Arabic and English research. Ph.D. dissertation, Oklahoma State University.

Ansari Moghaddam, S., \& Tan, B. (2014). Undergraduates' experiences and attitudes of writing in L1 and English. Journal of Language Studies, 14(1), 7-28.

Bacha, N. N. (1997). Patterns of lexical cohesion: A study of EFL students compositions at the Lebanese American 
University. Unpublished Ph.D. Thesis, Leicester, UK.

Bacha, N. N. (2002). Developing learners' academic writing skills in higher education: A study for educational reform. Language and Education International Journal, 16(3), 161-177. http://dx.doi.org/10.1080/09500780208666826

Belcher, D. D. (2006). English for specific purposes: Teaching to perceived needs and imagined futures in worlds of work, study, and everyday life. TESOL Quarterly, 40(1), 133-156. https://doi.org/10.2307/40264514

Bhatia, V. K. (2004). Worlds of written discourse: a genre-based view. London: Continuum.

Connor, U. (2002). New directions in contrastive rhetoric. TESOL Quarterly, 36(4), 493-510. https://doi.org/10.2307/3588238

Connor, U., \& Johns, A. M. (1990). Coherence in writing: Research and pedagogical perspectives. Washington, DC: TESOL.

Connor, U., \& Kaplan, R. (1987). Writing across language: Analysis of L2 text. Reading, MA: Addison-Wesley.

Connor, U., Nagelhout, E., \& Rozycki, W. (2008). Contrastive Rhetoric: Reaching to Intercultural Rhetoric. London: John Benjamins Publishing. https://doi.org/10.1075/pbns.169

Coulthard, M. (1994). Advances in written text analysis. London: Routledge. https://doi.org/10.4324/9780203422656

Feez, S. (1998). Text-based syllabus design. Sydney: McQuarie University/AMES.

Ferris, D., \& Hedgcock. (2004). Teaching ESL Composition: Purpose, Process, Practice. London: Routledge.

Grabe, W., \& Kaplan, R. (1996) Theory and practice of writing. New York: Longman.

Grabe, W., \& Kaplan, R. (2014). Theory and Practice of Writing: An Applied Linguistic Perspective. London: Routledge.

Hatim, B. (1997). Communication across cultures: Translation theory and contrastive text linguistics. Exeter, England: University of Exeter Press.

Hinds, J. (1983). Contrastive rhetoric: Japanese and English texts. Text, 3, 183-195. https://doi.org/10.1515/text.1.1983.3.2.183

Hyland, K. (2013). Faculty feedback: Perceptions and practices in L2 disciplinary writing. Journal of Second Language Writing, 22, 240-253. https://doi.org/10.1016/j.jslw.2013.03.003

Hyland, K. (2016). Teaching and researching writing (3rd ed.). London: Routledge.

Hyland, K. (2017). English in the disciplines: arguments for specificity. ESP Today, 5(1), 5-23. https://doi.org/10.18485/esptoday.2017.5.1.1

Jacobs, H. L., Zinkgraf, S. A., Wormouth, D. R., Hartfiel, V. F., \& Hughey, J. B. (1981). Testing ESL composition: A practical approach. Rowely, MA: Newbury House.

James, M. A. (2014). Learning transfer in English-for-academic-purposes contexts: A systematic review of research. Journal of English for Academic Purposes, 14, 1-13. https://doi.org/10.1016/j.jeap.2013.10.007

Jarvis, S., \& Crossley, S. (Eds.) (2012). Approaching language transfer through text classification: Explorations in the detection-based approach. Clevedon: Multilingual Matters.

Johns, A. (2001) (Ed.). Genre in the Classroom: Multiple Perspectives. London: Routledge.

Johnson, T. S., Smagorinsky, P., Thompson, L., \& Fry, P. G. (2003). Learning to teach the five-paragraph theme. Research in the Teaching of English, 18(2), 136-176. Retrieved from www.academia.edu/9155244/

Kaplan, R. (1966). Cultural thought patterns in intercultural education. Language Learning, 16, 1-20. https://doi.org/10.1111/j.1467-1770.1966.tb00804.x

Kaplan, R. (1987). Cultural thought patterns revisited. In U. Connor \& R. Kaplan (Eds.), Writing across languages: Analysis of L2 text (pp. 9-21). Reading, MA: Addison-Wesley.

Kroll, B. (1990). Second language writing: Research insights for the classroom. Cambridge: Cambridge University Press. https://doi.org/10.1017/CBO9781139524551

Lally, C. G. (2000). Writing across English and French: An examination of strategy use. The French Review, 73(3), 525-537. 
McCune, V. (2004). Development of first-year students' conceptions of essay writing. Higher Education, 47, 257-282. https://doi.org/10.1023/B:HIGH.0000016419.61481.f9

Mukattash, L. (2003). Towards a new methodology for teaching English to Arab learners. TEAL, 4, 211- 234.

Nor, N., Hua, T., \& Ibrahim, N. (2012). Investigating composing strategies in the project papers of Arab postgraduate students. Journal of English Language Studies, 18(3), 135-153.

Odlin, T., \& Yu, L. (2016). New perspectives on transfer in second language learning. Bristol: Multilingual Matters.

Paltridge, B. (200). State of the art review: Academic writing. Language Teaching, 37(2), 87-105. https://doi.org/10.1017/S0261444804002216

Petric, B. (2005). Contrastive rhetoric in the writing classroom: a case study. English for Specific Purposes, 24(2), 213-228. https://doi.org/10.1016/j.esp.2004.09.001

Purves, A. C. (1988). Writing across languages and cultures: Issues in contrastive rhetoric. Newbury Park, C.A.: Sage.

Sa'adeddin, M. A. (1989). Text development and Arabic-English negative interference. Applied Linguistics, 10(1), 36-51. https://doi.org/10.1093/applin/10.1.36

Swales, J. M. (1990) Genre analysis: English in academic and research settings. Cambridge: Cambridge University Press

Van Weijen, D., Vand den Bergh, H., Rijlassrsdan, G., \& Sanders, T. (2009). L1 use during L2 writing: An empirical study of a complex phenomenon. Journal of Second Language Writing, 18(4), 235-250. https://doi.org/10.1016/j.jslw.2009.06.003

Wang, W., \& Wen, Q. (2002). L1 use in the L2 composing process: An exploratory study of 16 Chinese EFL writers. Journal of Second Language Writing, 11, 225-246. https://doi.org/10.1016/S1060-3743(02)00084-X

Woodall, B. (2002). Language-switching: Using the first language while writing in a second language. Journal of Second Language Writing, 11, 7-28. https://doi.org/10.1016/S1060-3743(01)00051-0

Zamel, V. (1997). Towards a model of transculturation. TESOL Quarterly, 31, 341-343. https://doi.org/10.2307/3588050

\section{Appendix A.}

\section{Student Questionnaire on Causes of L1 Interference in Essay Writing}

Dear Student,

This is research into your writing essays in English. It is voluntary and confidential. Please fill out to the best of your knowledge. Thank you.

- Age:

- Major:

- Nationality (ies):

- Gender: Female _ _ Male

- Which language medium did you study in at high school?

- Arabic French English Armenian Spanish

- Others: (please specify)

- What is your native language(s)?

- Arabic French English Armenian Spanish

- Others: (please specify)

- What language(s) do you speak well?

- Arabic French English Armenian Spanish

- Others: (please specify)

- What language(s) do you write well? 
- Arabic French English Armenian Spanish

- Others(please specify)

Circle the number that best fits your answer

$1=$ Never $\quad 2$ = Rarely 3 = Sometimes

$4=$ Most of the time $\quad 5=$ Always

\begin{tabular}{|l|l|lllll|}
\hline 1 & When I write in English I translate from Arabic in my mind & 1 & 2 & 3 & 4 & 5 \\
\hline 2 & When I write in English I translate from French in my mind & 1 & 2 & 3 & 4 & 5 \\
\hline 3 & When I write in English I translate from Armenian in my mind & 1 & 2 & 3 & 4 & 5 \\
\hline 4 & When I write in English I have problems in organizing my ideas & 1 & 2 & 3 & 4 & 5 \\
\hline 5 & When I write in English I have problems in vocabulary & 1 & 2 & 3 & 4 & 5 \\
\hline 6 & When I write in English I have problems in grammar and sentences & & & & \\
\hline 7 & My essay writing problems are because Arabic is my native language & 1 & 2 & 3 & 4 & 5 \\
\hline 8 & My essay writing problems are because I am French educated & 1 & 2 & 3 & 4 & 5 \\
\hline 9 & My essay writing problems are because I do not know how to write essays & 1 & 2 & 3 & 4 & 5 \\
\hline 10 & I earn grades over 80\% in my essay writing & 1 & 2 & 3 & 4 & 5 \\
\hline
\end{tabular}

\section{Copyrights}

Copyright for this article is retained by the author(s), with first publication rights granted to the journal.

This is an open-access article distributed under the terms and conditions of the Creative Commons Attribution license (http://creativecommons.org/licenses/by/4.0/). 